\title{
THE GERM PLASM OF THE OSTRICH
}

\author{
PROFESSOR J. E. DUERDEN \\ Rhodes University College, Grahamstown, South Africa
}

$A$

The germ plasm is fundamental and remarkably conservative . . . when the germ plasm changes it does so as a result either of wholly internal physiological causes, or of very extraordinary environmental stresses acting directly upon the germ cells . . . mixing of germ plasms, in and of itself, does not mutually alter hereditary determiners ... selection only acts as a mechanical sorter of existing diversities in the g'erm plasm and not as a cause of alteration in it.

\section{$B$}

Hereditary determiners or factor's fluctuate regularly and frequently, if not indeed usually, and in high correlation with somatic characters ... mixing of germ plasms in fertilization alters hereditary determiner's mutually and hence is, in and of itself, a cause of genetic variations . . . a purely external agent, the continued selection of personal somatic qualities, will alter the germ plasm.

IN $_{\mathrm{N}}$ the above clear, concise phrases, sometimes with supporting amplification, Dr. Raymond Pearl, ${ }^{1}$ in the presidential address before the New York Meeting of the American Society of Naturalists, 1916, contrasts the attitude of two sections of American geneticists with regard to the manner of changes in the germ plasm, as affording so much somatic material upon which selection may possibly work in the evolution of animals and plants.

So much evidence is already available for discusision on the merits of the one side or the other that it would appear gratuitous to adid more, and one can well appreciate the advice which Pearl gives to get down to more, and more searching, investigations as to the causes of genetic (factorial) variation. The case of ostrich breeding in South Africa however affords such direct evidence bearing upon

1"The Selection Problem," AmErican NAturalist, February, 1917, Vol. 51. 
most of the dicta that it is thought an account may be welcomed by geneticists. At any rate it may be added to the already voluminous "Experience of Practical Breeders," containing facts which will need to be reckoned with in any explanation of the actual causes of germinal changes. The ostrich affords an example of an animal only recently domesticated and still in the making, and we have before us the practical methods followed and the results obtained, enabling us to deduce in some measure the genetic principles involved. The endeavor will be to see what contribution its germ plasm has to make to each of the contrasting statements at the head of the paper, not forgetting that we know but little of the nature of the germ plasm and its changes except from their manifestation in the soma. It may be there is truth in both attitudes.

"The germ plasm is fundamental and remarkably conservative."?

Ostrich farming on methodical lines was first undertaken in South Africa about fifty year's ago. The beginningss were made with chicks obtained from wild nests, as unless "tamed" from an early age control of the adults is afterwards impossible. So remunerative did the industry prove to be that with the exception of one or two setbacks it advanced with great rapidity until at its zenith, the year before the war, 1913, nearly 1,000,000 domesticated birds were recorded, yielding an export of 1,023,307 lbs. of feathers at a value of $\$ 15,000,000$, forming with gold and diamonds a triad contributing much to the prosperity of South Africa. With the advent and continuance of the war depression of a most severe character set in among ostrich farmers, and the number of birds has been reduced by about two thirdis.

In the early days of the industry very little account was taken of the quality of plumage produced, and any bird reaching sexual maturity (three to four years) was employed as a breeder. Within the past two or three decades 
however the greatest attention has been devoted to the many characters of the plume and only the best plumage birds have been employed as breeders, the chief reason being the great difference in returns from clippings of high quality compared with those of an ordinary or inferior type. An intensive study has arisen in connection with the various structural details of the feather and also with the measures necessary for their production in the highest state of excellence; among the latter are included both the feeding and management of the birds as well as selection in breeding. It is probably safe to say that no domestic animal has been more intensively and intelligently studied by the farmer than the high grade ostrich, or more pampered in its treatment. Breeding sets, a cock and a hen, known to produce progeny giving superior plumag'e have frequently realized as much as $\$ 5,000$.

The "points" of the ostrich plume relate to details concerning the length, width, density, lustre, shapeliness and evenness of the flue (vanes) and the form and strength of the shaft, and a highly technical terminology has arisen in connection therewith. An ostrich produces annually from 200 to 300 commercial feathers, belonging to a dozen or more different classes-whites, byocks, blacks, drabs, floss, tails-each with its many subdivisions. Each individual feather is handled and specially examined several times in the processes of clipping, arranging, sorting and selling, before being exported, and prior to the war two or three hundred millions of feathers were in this manner passed in review.

Under such keenly discriminating circumstances it will be understood that if any plumage variation presented itself it would be at once recognized and brought to general notice. A bird giving rise to a departure of any moment in a desirable direction in connection with any of the feather points mentioned would represent a fortune to its owner. But not a single case has ever been forthcoming. Without any hesitancy it can be affirmed that in the course of the fifty years during which the ostrich has 
been domesticated it has never produced a feather variation, germinal in its origin, such as could be regarded as of the nature of a sport or mutation. Feather irregularities and abnormalities are by no means infrequent, but can generally be ascribed to some injury to the feather germ or follicle in the process of quilling, or to malnutrition. Any peculiarity of this nature is usually forwarded to the writer, and some of the more common irregularities have already been described. ${ }^{2}$ They are never hereditary peculiarities.

This stability on the part of the various structural details of the feather has continued despite the great changes to which the ostrich has been subject as a domesticated creature. The birds are fed on the most nourishing and stimulating of foods, the farmer having no option in the matter if he is to secure a feather crop of the highest quality; also they may be transferred from the moist coastal planes to the dry and arid interior at an elevation of 5,000 or 6,000 feet, a change involving great variation in temperature, pressure and other conditions. As an epidermal product, growing at the rapid rate of a quarter of an inch daily, the feather is extremely sensitive to changes in nutrition and climatic conditions, often responding to the small differences in blood-pressure between day and night. Yet all the modifications resulting, from these influences are somatic; no hereditary germinal alteration has ever manifested itself.

Like so many other African animals, the giraffe, hippo, rhino, elephant and ant-bear, the ostrich is a survival of ancient days, a left-over, and as becomes a creature of long ancestry is fixed and immutable with regard to the many characteristics of its plumage. Numerous germinal changes have appeared in the past and survive to-day in the various feather types recognized by the specialist, all of which breed true; but it can justly be claimed that no further alteration has taken place during the pasit fifty

$2^{2}$ "Experiments with Ostriches, XXI., F'eather Irregularities," Agric. Journ., Union of South Africa, August, 1912. 
years, in spite of the many environmental changes to which the bird has been subject. As regards the structural details of the feather the germ plasm of the ostrich fully confirms the statement with which the section opens.

"Mixing of germ plasm, in and of itself, does not mutually alter hereditary determiners."

If the plumage characters of the ostrich are so immutable what then is the objective in breeding'? The original wild stocks with which the farmer commenced in the sixties differed much among themselves in the structural minutix of the feather, and the most desirable of the various feather points were distributed among many strains. The earnest endeavor of the ostrich breeder is to combine in the single plume the best of all the many desirable features originally scattered throughout the wild birds. The ultimate purpose of every breeder is the same-to produce a plume combining the maxima of all the available feather characters; a plume having the greatest length, width, density and luster and the most perfect shape, supported on a round, strong, slender shaft. On the original birds the largest plumes had for the most part a coarse, loose, unshapely flue, while the most compact, shapely, lustrous, graceful plumes were generally small. The whole effort is to combine the maximum size with all the so-called "quality points", no other feature of the bird is taken into account in breeding, as none has any commercial value or is known to be in any way correlated with feather production. The problem appears simple, though it is taking years to accomplish; progress is being made each year, but the ideally perfect ostrich plume is not yet.

The genetical methods of the farmer are. likewise simple. He proceeds entirely in the belief of a blending inheritance, which though doubtful in theory is succeeding in practise. He starts with a bird which produces plumes the most nearly approaching his ideal, and mates 
it with another most closely resembling it, but perhaps lacking or surpassing in one or more points; another season he may resort to a different mating to secure other features. From different breeding sets he may rear two or three hundred chicks in a season. The progeny being' mostly intermediates and showing much variation he selects when mature the most desirable among them as breeders, or maybe, being weak in some particular point, he will purchase or exchange with another breeder in whose birds the character is strong. By this method, essentially one of hybridization, the ideal plume is being slowly built up. Sometimes by a fortunate mating one breeder will be ahead and sometimes another, a successful competitor at a Feather Show being inundated with orders for breeding birds and chicks and his fortune well assured. Despite the variability in the progeny no breeder can afford to "fix" his strain by a measure of inbreeding, lest while doing this another may get ahead. Taking all the economic and biological circumstances into account the geneticist has little he can contribute to such a practical effort; he can but assist by endeavoring to deduce and explain the principles involved.

The textual application is manifest. The greatest mixture of germ plasm is going on, but no single hereditary factor or determiner is altered in the process, and has not altered throughout the history of ostrich breeding; only new combinations are formed of factors alveady avalable. The farmer himself has long grasped this and does not look for any change; he knows he can get nothing beyond what the wild bird had to start with; he can create or change nothing, beyond what can be ascribed to good management and feeding. For practical purposes his understanding of the individuality and fixity of the germ factors producing the plume is as clear as that of the most zealous Mendelian; but only in a few instances has he ever heard of the factorial hypothesis, though facts upon which it could have been established were discovered in his farming practise long before 1900, the year of Men- 
delian reawakening. If his birds, judging by their feather performance, are lacking a certain germ factor he is well aware that he can by no possible means originate the factor nor hope to produce it in any way; he must procure it from some other farmer whose birds display it, and then he may expect to secure it in combination in his own strain.

\section{III}

"Selection only acts as a mechanical sorter of existing diversities in the germ plasm and not as a canse of alteration in it."

The term "selection" is employed by the ostrich breeder in South Africa with all that freedom which Pearl finds among the plant and animal breeders in America, but he is never under any delusion that it signifies more than is implied in the simple meaning of the word. $\mathrm{He}$ has retained its plain everyday significance and the majority have never heard of Darwin and "The Origin of Species by Means of Natural Selection,', nor of the extended meaning which students of evolution are inclined to give the term, as in the phrase, "The Selection Problem." To the ostrich farmer "breeding from selection", simply means that for his breeding sets he picks out birds having the special plumage characters he desires to see in their progeny, or which he expects to get from the combination of the cock and the hen. Selection is merely used in contrast with indiscriminate breeding, as where any cock and hen may be camped off without regard to their plumage value, or in contrast to breeding on the veld where any cock may mate with any hen. He selects partly on the basis of somatic performance and partly on proved germinal production; many birds which themselves give indifferent plumage are yet employed as breeders from being known to produce superior chicks.

From his life-long experience in selective breeding the ostrich farmer clearly grasps that all he is doing is to sort out birds from among his flock with certain characters 
which he desires to see in combination in their progeny, but he never dreams that any change in the characters themselves will result therefrom. Though perhaps unable to express it in wordis he knows that the germ plasm of each of his birds contains so many factors, and in his selection of breeders picks out the birds having the factors he desires to give him new combinations, but he has no expectancy that the factors themselves will undergo any change as evidenced by their expression in the progeny. Selection along the prescribed lines is probably as rigid as that which any experimentalist could carry out, and is certainly more so than can be conceived of as taking place in nature, yet long as it has been in operation it has never carried with it an alteration of any of the existing diversities of plumage.

\section{IV}

"When the germ plasm changes, it does so as a result either of wholly internal physiological causes, or of very extraordinary environmental stresses acting directly upon the germ cells."

"The bodily characters' of the South African ostrich present a remarkable uniformity except as regards certain details to be described later, but in comparison with the North African bird many striking differences appear. In 1912 the Government of the Union of South Africa imported 132 specimens of the northern ostrich from Nigeria. It was hoped that in these some one or other of the plumage characteristics might be developed to a higher degree than in the southern bird and could with advantage be combined with the latter. Experiments with this end in view are now in progress under the direction of the writer.

The northern ostrich is longer in the legs and neck than the southern, the head reaching a little over eight feet from the ground, about a foot more than in the latter. The color of the skin of immature birds of both sexes and of mature hens is a creamy yellow, while the mature cock 
is bright red or scarlet on the legs, head and neck, and red and pink over the body generally; in the southern ostrich the skin of the neck, body and.legs is a pale yellow in chicks, dark gray in mature hens and dark blue in cocks, while in the sexually ripe cock only the beak, the front part of the head, the naked skin around the eyes and the tarsal scales are a bright scarlet. The crown of the head of the northern bird has a bald oval patch while that of the southern is covered with hair-like feathers similar to those over the rest of the head and neck. The northern egg is larger and rounder, with an enamel-like smoothnesis, and is practically free from obvious pittings; the southern is deeply pitted all over, smaller and more oval. Knowing as' we do the habits and life of the ostrich it is in the highest degree improbable that any of the differences have an adaptive significance or selective value in nature.

When the birds are observed side by side, as can now be done at Grootfontein, the above characters readily serve to separate the northern from the southern ostrich, and may well be held to justify the specific distinction usually accorded them. That the distinguishing features of the former are not environmental but germinal is proved by the fact that they: persist under southern conditions and have reappeared in progeny already reared. Numerous cross-breds or hybrids of the first generation have also been obtained, but sufficient time has not yet intervened to secure the second hybrid generation. As regards dimensions, color and the nature of the egg the first generation of cross-breds are intermediates in varying degree between the northern and southern parents, but the bald head patch of the northern is dominant over its absence in the southern, appearing in all the crosses yet reared.

It is clear that the germ plasm of the northern ostrich has undergone marked chang'es compared with that of its southern representative, or vice versa, for one can only think of the various races or species of Struthio as derived from a common stock. In terms of the sectional heading we may well enquire whether the changes are due to 
internal physiological causes or to extraordinary environmental stresses acting upon the germ cells. We have already seen that germinally the South African ostrich is most irresponsive to any environmental changes and we have no reason to suspect that its northern relative is in any way more impressionable. In the climatic and other environmental conditions of North Africa it is difficult to conceive of anything which could, for example, modify the bodily colors as compared with those of the southern bird, or could bring about a perfectly smooth round egg in contrast with an oval pitted one, much less' which could either directly or through the soma change the germ cells so as to render the differences hereditary. Of course we know next to nothing of the influence upon the germ cells of extraordinary environmental stresises and to labor the point would be unprofitable. But doubt may certainly be expressed as to whether any external influence could so change them as to bring about the formation of a bald head patch, a feature which it is impossible to regard as having an adaptive significance. It is a new germinal character which has appeared in the northern bird, entirely sui generis; there is nothing suggestive of it in the southern ostrich.

We have the hard fact to account for that the germ plasms of the northern and the southern ostrich differ from one another in certain respects as revealed by their manifestation in the soma, and it is also proved that they breed true irrespective of environment. And while in our condition of absolute ignorance no good purpose will be served by dogmatizing it may be permitted to express the conviction that the germ plasm changes as between the northern and southern ostrich have resulted entirely from internal physiological causes. The conviction is strengthened all the more from the facts to be presented in the next section. 


\section{$B^{3}$}

\section{$\mathrm{V}$}

"Hereditary determiners or factors Auctuate regularly and frequently, if not indeed usually, and in high correlation with somatic characters."

In a certain measure this statement may be looked upon as opposed to that with which section 1 opens, but no one would maintain either the one or the other to be the exclusive state of the germ plasm, hereditary determiners or factors of all animals and plants. We have abundant evidence that the germ plasm is remarkably conservative for some forms of life (persistent types) while in others it may fluctuate or change frequently (Drosophila); also, it is not unreasonable to expect that at any one period the factors for certain parts of an organism may remain fixed while for others they may be in a state of change. We have seen that the factors controlling the structural details of the ostrich plume are peculiarly constant, but the endeavor will now be made to establish that those for the wing feathers numerically, as well as for certain other parts of the bird, are undergoing regular and frequent changes and in determinable directions.

By zoologists the wing of the ostrich is usually regarded as degenerate, on account of its small size compared with the body and legs and the practical absence of any covering of feathers on its inner or under surface. Certain studies recently made have given good reason for concluding that in many other less obvious respects it is still undergoing degeneration. The full details upon which

3 The three statements under section B are obviously considered by Dr. Pearl to apply specially to Dr. Castle's claims in connection with his experiments on piebald rats, a condensed account of which appears in the same issue of the NATURALIST as Pearl's paper (p. 102). Instead of regarding them as applicable only to the disputed plus and minus fluctuations in the factor itself it may be permissible to consider them in a broader sense, as referring to the nature of the germ-plasm generally and as contrasted with those in section A. What follows has probably no connection with results such as those which Castle has obtained but nevertheless it is hoped to show that real factorial changes, continuously retrogressive in their nature, are going on in the germ plasm of the ostrich and that there is much likelihood the changes can be influenced by selection. 
the claim is based will appear later. Only the outline of the facts can now be given in so far as they bear upon the condition of the germ plasm.

Only a single row of under-coverts usually occurs on the wing of the ostrich, its members alternating with the remiges or wing quills (Fig. 1). In but two specimens out of hundreds examined however has the full number of feathers required for alteration with the complete row of remiges been found. Usually eight to ten are missing from the elbow end of the row, though the number varies, and occasionally two or three vestigial feathers may appear between the normal members and the missing sockets. Single plumes are at times met with in front of the row and are obviously representatives of a second row, while in one farmer's strain an almost complete second row of under-coverts occurs, alternating with the first, and in front of this are five or six members of a third row. One is forced to the conclusion that the ancestral ostrich had the under surface of its wing's provided with several rows of under-coverts in the same manner as modern flying birds, and that the rare occurrences mentioned are in the nature of survivals, the germinal factors responsible for their appearance having been largely, though not yet altogether, lost to the race.

The valuable wing quills or remiges ordinarily vary from 33 to 39 , having the same average, about 35.5, for both the northern and southern birds. They constitute a fluctuating series about the mode 36 , though there is much probability that each separate number in the series will be found to represent a pure line. Assuming that not much numerical variation occurs in the plumes of the ostrich the farmer has never yet bred for quantity, quality has been his only consideration. Recently however a cock bird has been discovered among the government's experimental troops bearing 42 remiges, and it is submitted that this high number represents an ancestral survival rather than a reversion or mutation, and that the wing quills of the African ostrich afford us various stages in degenera- 


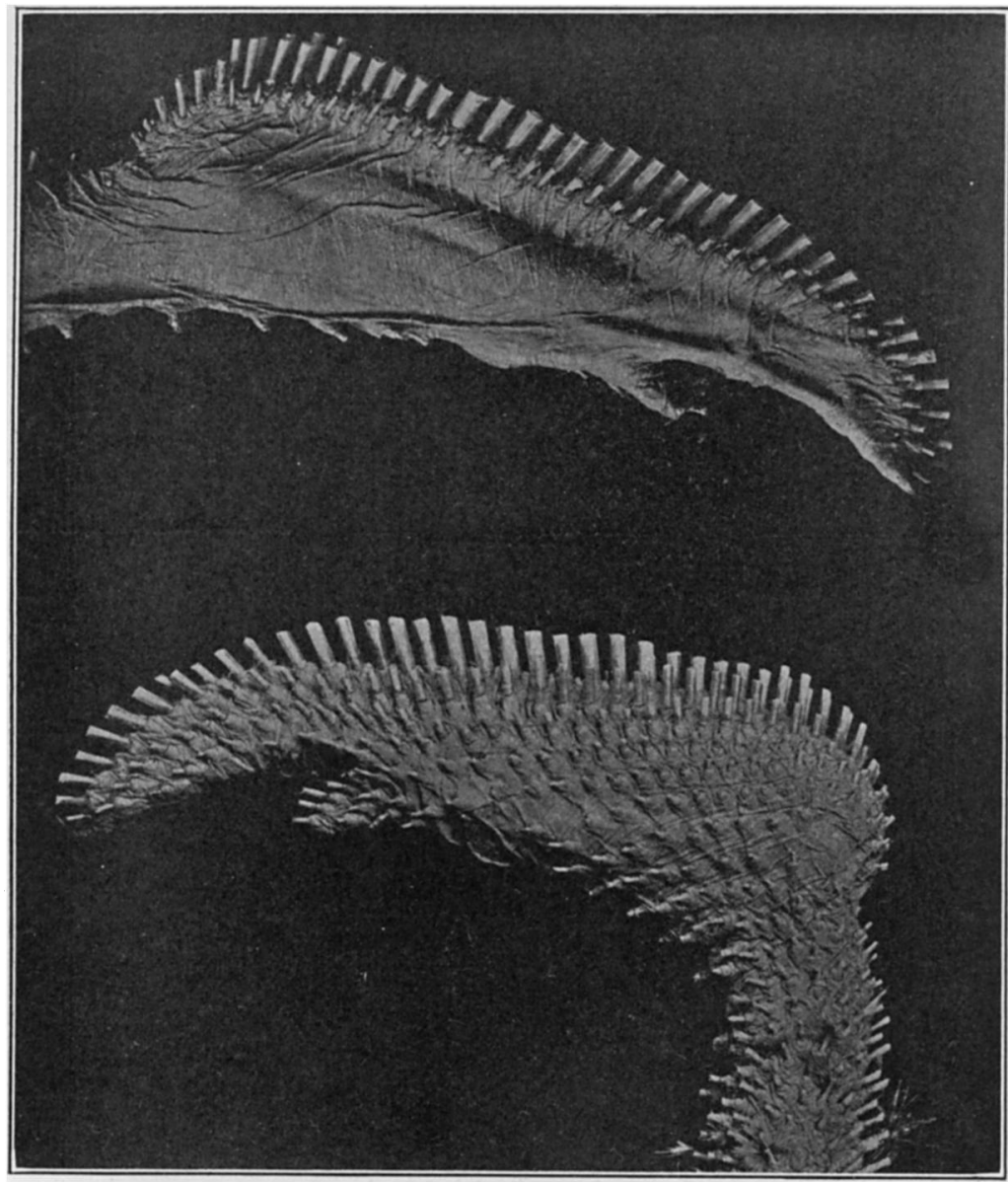

FIG. 1. Under surface of wing of ostrich with plumes clipped off. In by far the majority of ostriches the surface is naked except for the single row of under-coverts which is rarely complete; in the specimen represented six of the coverts are missing from the elbow end of the row. In one farmer's strain an almost complete second row of under-coverts occurs and also a few members of a third row. The third digit is almost buried in the flesh of the wing, but can be seen projecting slightly towards its distal end. The claw which is present on the first and second digits is not clearly shown.

FIG. 2. Outer surface of wing of ostrich, the plumes having been clipped off to show their arrangement in rows. The feathers in the uppermost row, the wing quills or remiges, vary from 42 to 33 in different birds. The members of the first row of upper-coverts alternate with the wing quills and vary with them in number, while the second row of coverts has often a number missing towards the free end of the row, though not in the wing represented. The other rows of coverts, third, fourth and fifth, may also show reduction. The marginal row of the bastard wing may contain from two to seven feathers. 
tion from the maximum 42 to the present minimum of 33 . As experiments have proved that the high number breeds true, and as the other rows of commercial plumes vary in correlation with the remiges, the discovery has a great industrial bearing; for it now becomes possible to provide the farmer with a pure line of 42-plumed ostriches in place of the deg'enerate 36-plumed birds with which he farms to-day, and the entire feather crop will surpass the present one by about 25 per cent.

The first row of upper-coverts varies in correlation with the remiges (Fig. 2) but never shows any independent reduction, while the second row has often a number missing from its distal end, and is clearly undergoing reduction here in contrast with the elbow end for the under-coverts. Again, it is usually stated by writers that the ostrich is destitute of an under-covering of down feathers and filoplumes, yet in every northern ' and southern bird examined, down in all stages of degeneration occurs around the base of the larger plumes of the wing and tail, andin rare cases spreads over a wider area, leading to the conclusion that at one time the ostrich had an under-covering of small feathers like flying birds generally.

The third digit displays certain most unexpected evolutionary stages. While in most cases it is altogether embedided in the flesh of the wing, and can only be seen and felt through the thin skin, yet occasionally its tip projects quite freely, suggesting its former separation, like the first digit which forms the ala spuria. Moreover, in some birds odd feathers are to be found set along the finger, altogether detached from any other series. These are surely to be understood as survivals of a time when the third finger was clawed, free and provided with its own feathers, a primitive condition which is usually held to be represented only in the oldest known fossil bird, Archcoopteryx.

The legs and toes likewise exhibit degenerative phases. The African ostrich is unique among living birds in hav- 
ing already lost its first, second and fifth toes, only the third and fourth remaining. The outer, fourth toe is far smaller than the inner third toe, and the condition of its

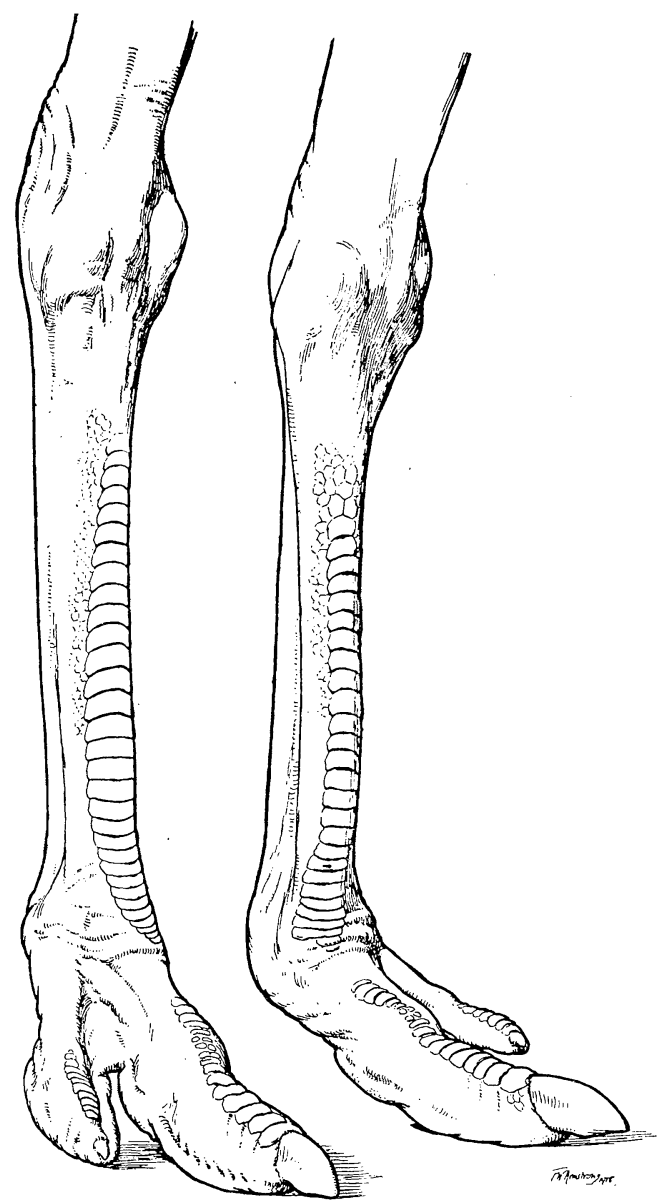

Frg. 3. Tarsus and foot of North African ostrich. The outer, fourth toe is greatly reduced in comparison with the inner, third toe. The former shows a small non-functional claw. A distinct break occurs between the scutellation of the tarsus and that of the middle toe, though in most ostriches the two series of scales are continuous. A second break is beginning to form over the middle joint of the toe, the larger scales being divided into two or three smaller ones.

claw as well as its smaller size lead one to infer that it also is on the road to disappearance (Fig. 3). In northern birds the claw of the fourth toe is frequently discernible, though altogether functionless, never reaching the ground; 
but on only a few southern birds is it ever seen, and then in a most vestigial state, barely showing beyond the skin.

What may doubtless be regarded as the first steps in the degeneration of the big middle toe are also displayed. Down the front of the tarsus extends a series of large, nearly rectangular scales, continuous all the way from a little below the ankle and passing over the upper surface of the toe, though usually somewhat smaller where the toe joins on to the tarsus. In a few ostriches a distinct break occurs at the joint, several large scales being altogether wanting (Fig. 3), and rarely birds are met with in which a second break takes place over the middle joint of the toe. One may hazard the suggestion that the interruption in the scutellation over the two joints has an adaptive significance, allowing the parts to move more freely, but we have also to face the fact that the single break occurs in but a few while the double break is very rare. It is presumably a new feature in course of introduction into the ostrich race, but not yet established for the members as a whole. It involves however a reduction in the make-up of the toe; it is a minus or retrogressive mutation, and may well be the first hint of impending loss of what will be the only toe when the small fourth has gone.

Although definite experimental data on all these reduction phenomena are not yet available everything points to the fact that the variations breed true and are therefore germinal in their nature; they are certainly not ordinary fluctuating somatic variations. Proof is to hand that the 42-plumed cock has factorial representation for its high number of plumes. Another similarly numbered hen is not yet available, but in crosses with various 36-plumed hens the average number of plumes of the progeny is 39.56 which is midway between the parents, while the mode is 40. Considering the heterozygous nature of the ostrich where number of plumes is concerned a fluctuating series of this kind is what would be expected. Only one farmer's strain has the nearly complete second and third rows of under-coverts, but they are found in all the progeny from 
the strain; all the members of a flock bred from the same stock have the second row of upper-coverts complete, while in other flocks all the members have a number of plumes absent from the row. Crossing of birds in which the complete loss of the claw on the small toe has taken place with others in which the claw still appears gives results on strictly factorial lines, as also does the crossing of birds with and without a loss of the scales. In a mixed assemblage of any species where only a small proportion display a certain character it may be presumed that the latter will be heterozygous with regard to the particular character, seeing that the chances are much against the mating of two individuals each having the character. The heterozygous nature of the bird can be demonstrated on mating with one in which the character is absent, for if dominant it will appear in half the progeny and be absent from the others. This proportion with regard to the presence of the claw and the loss of the toe scales has been found to hold in all the crosses. Out of a total of 36 chicks hatched from breeding pairs where one parent was clawed and not the other the numbers were actually equal, namely, 18 chicks were clawed and 18 unclawed. Out of 11 chicks reared from a pair where one parent showed no loss of scales on the big toe and the other had a single break, 5 had no break and 6 showed the break.

It may be accepted then that all the degenerative phases represent factorial changes which have come about in the germ plasm of the ostrich. Presumably the changes involve a loss of factors; they are retrogressive or negative mutations. Structures which would be expected to occur either fail to appear or are seen very rarely, and may then be regarded as survivals, the factorial losses not having yet taken place in the particular individuals. Thus, to take the case of the first row of under-coverts, the principle of alternation demands that a complete row of under-coverts should alternate with the row of remiges. The full row actually occurs in a few individuals, and 
suffices to prove that this was the condition in the ancestral ostrich; more usually eight to ten are missing and also fail to appear in the progeny. It is therefore reasonable to assume that the germ factors originally involved in the production of the eight to ten under-coverts have disappeared from the majority of ostriches though they are retained in a few. The fact that all the intermediate numbers can yet be obtained show's the loss to have been progressive. A similar line of argument can be applied all through. Loss or degeneration is in progress in various directions and differs in degree in different individuals, and the losses are the outward expression of internal changes in the germ plasm.

Where a loss of factors is taking place it could hardly be expected that all the individuals of the race would be affected at one and the same time. The process would be more rapid in some than in others, some would incur the loss at one time and some at another, and the results from crossing would need to be reckoned with. Hence we can understand the great diversity of stages represented in the ostrich where large numbers are available for examination. It may be hard to comprehend how in the first instance germinal changes can be brought about, but if once effected, their repetition and continuance can reasonably be expected. Beginning with one or a few birds it is manifest that as the loss in any direction continues more and more individuals will become affected, until in the end complete loss for the race will be achieved. So far as the investigation of farmer's troops has proceeded it affords strong evidence for the view that only one original 42-plumed bird now exists in South Africa, so that under natural conditions the extinction of this high number of remiges would be imminent. The loss of the claw from the third finger is probably only recent. Some textbooks of zoology $\mathrm{y}^{4}$ assert that a third claw occurs, but it has never been found on the hundreds of southern and northern ostriches coming under my examination, although specially looked for.

4 Parker and Haswell, Vol. II, p. 393. 
In most instances it would appear as if the loss of all the many factors concerned in the production of a single plume takes place simultaneously, as is the case with most meristic structures; for usually the absences are complete plumes. In some birds, however, two or three incompletely formed or vestigial feathers occur between the normal feathers of a row and the absent sockets, as if the loss of the individual plume were taking place piecemeal. This condition can be easily understood if we assume that the constituent factors concerned do not all drop out together, but follow some sort of succession. The factors left at any time would then give rise to the part of the feather for which alone they are responsible, and we should get an imperfect or vestigial feather. In any animal vestiges of a structure will continue to appear so long as any of the factors concerned in the original structure remain. It is submitted that degeneration of any complex structure never takes place in a gradual continuous manner, as is usually supposed, but by successive steps determined by the manner in which the factors drop out; the appearance of continuity will however be conferred if the steps are small enough.

If a sufficient number of individual ostriches were gathered together it could easily be made to appear as if degeneration in any of the recognized directions were taking place in a slow continuous manner, for all stages between the extremes could be obtained. Proceeding by such a method however would give an erroneous impression of what is actually happening. For although all stages do occur they are in reality disconnected, and each stage has been reached in an individual quite irrespective of the others, and represents a separate and distinct germinal loss; furthermore, in the same individual degeneration in any one direction proceeds quite independently of the other directions in which the process is taking place. It is not the wing as a whole which is undergoing degeneration, but the constituent parts of which it is made up, each presumably represented by its own factors and be- 
having with a large measure of independence. The losses are continuous for the race but discontinuous for the individual; and it is with the individual that heredity is concerned and evolution with the race.

The degeneration phenomena presented by the ostrich in connection with its wings and legs, as well as with its plumage, would appear to provide us with an example of the application of mutative and Mendelian principles to such evolutionary facts as confront the comparative anatomist and paleontologist. So far as concerns the individual bird the retrogressive changes are shown to occur as separate mutations and to follow definite factorial lines, while as concerns the evolution of the race they proceed in a continuous determinate manner. In all probability they take place wholly irrespective of any adaptive significance or consideration for the welfare of the bird, and are intrinsic in their nature and uninfluenced by external conditions. Natural selection has probably played no part in connection with the losses, for the greater changes have already affected the race uniformly and the smaller ones which still vary in degree in different individuals will probably affect the whole in the end. Should the loss of plumage continue to a much further degree and marked degenerative changes be set up in the big middle toe natural selection may then be expected to bring about extinction.

The chief point desired to establish at present is that as regards the number of its wing plumes and in certain other features the ostrich affords strong support for the view that its hereditary determiners or factors are changing regularly and frequently; they are not fixed and constant as are the factors for the structural details of the plumes; one series is in a state of change, the other is nonchanging. The great variety and degree of the degenerative stages in the ostrich of to-day admits of no question, and that they are the expression of so many germinal differences may be accepted, seeing that they breed true; that they have been effected simultaneously as we find 
them is inconceivable, and we are justified in concluding that in the past the germ plasm has changed frequently and presumably over a long period. Moreover, we can hardly admit that the various degenerative phases will remain as they are at present, but that further losses in the same direction will follow, that is, the germ plasm will continue to undergo retrogressive changes of a like character to those already initiated. We may have an appearance of continuous change, but when analyzed it will be found to proceed by means of separate factorial steps. It is conceivable that a continuance of the kind of factorial losses now in progress will result ultimately in the complete disappearance of the wings and legs of the ostrich, allowing that the bird could survive the intermediate stages, a postulate which it must be conceded is of no mean order. May we not suppose that the limbless condition of snakes and some lizards, amphibians and fishes has come about by the successive losses of germinal factors in a similar manner to that which is here shown to be taking place in the ostrich?

The bearing of the germinal changes involved in the degenerative processes upon the thesis of Section IV, may be noted. It is in the highest degree improbable that determinate losses of such a widely embracive nature are taking place in response to any environmental stress acting upon the germ cells; rather they may be regarded as the result of some wholly internal physiological cause. If due to environmental stress one could reasonably expect that in any individual the losses would be taking place in all directions simultaneously, and would have reached about the same degree in all. But among the various rows of feathers, as well as in other parts, the greatest independence in reduction is met with, as if the factors for each were subject to a separate rather than a common influence.

\section{VI}

"Mixing of germ plasms in fertilization alters hereditary determiners mutually and hence is, in and of itself, 
a cause of genetic variations . . . a purely external agent, the continued selection of personal somatic qualities, will alter the germ plasm."

It seems to be generally allowed that at any period the majority of forms of life are static so far as germinal alterations are concerned, while some are undergoing progressive changes and others retrogressive changes. During the present period the representatives of the widely distributed Ratitæ are unquestionably undergoing marked changes and have been for ages past. The changes are in a negative or retrogressive direction, and express themselves in somatic degeneration, particularly with regard to the wing and shoulder girdle. The living Apteryx is a well-known instance of wing degeneration, as also the recently extinct moas, in which no hint of a wing has been found and a trace of the glenoid cavity only in one species. From the data already submitted we are able to learn something as to the manner in which the degenerative processes are proceeding in the wing and leg of the ostrich, and presumably the same method holds for the Ratitæ generally. Factors are evidently in process of dropping out, in regular succession, along definite prescribed lines, the degree varying much when the entire race is taken into account.

All Mendelian writers seem to concede that the factorial changes, plus or minus, are not autonomous on the part of the factors, but are "a result either of wholly internal physiological causes, or of very extraordinary environmental stresses acting directly upon the germ cells.' Though the results of Morgan and his associates indicate that it may yet be possible to understand the manner in which the factors undergo their changes it will always be competent for us to enquire as to the cause or causes inducing the changes. To be complete our analysis of variability will need to get beyond the factors to the force or forces acting upon them. In the previous sections good reason has been adduced for supposing that the losses going on in the germ plasm of the ostrich are 
due to some wholly intrinsic cause, and seeing that it affects all the members of the race and has been operative for a long period we may conclude that it is transmissible and acts continuously from generation to generation. The many stages represented also give some justification for supposing that whatever the cause of the factorial changes may be it varies in intensity in different members of the race, being less active in individuals where the loss of plumes is small as compared with others in which the loss is greater. For example, the causative agent bringing about the loss of the plume factors must be less in intensity or less active in 42-plumed ostriches than in ,33-plumed birds. We may with good reason expect that the selection for breeding of the high numbered birds will arrest the rate of degeneration of the race in this particular feature, while on the other hand the selection of the low-numbered birds will tend to accelerate the rate at which the factorial losses are taking place. Where therefore the germ plasm of a race is in a continuously changing phase, as in the ostrich, we can hope to retard or accelerate the changes by selecting individuals differing in the degree to which they are under the influence of the causative agent. It is submitted that in this sense we can say that "a purely external agent, the continued selection of personal somatic qualities, will alter the germ plasm.",

We can not hope that the continued selection of 42 plumed birds will in the end give to the farmer ostriches with a still higher number of remiges, as the factors for the plumes beyond these have in all probability disappeared from the race, and there is no evidence that the cause of the factorial changes is effective in a plus but only in a minus direction. On the other hand the continued selection of 33 -plumed birds may reasonably be expected to accelerate the loss of the remiges, by leading to a more rapid loss of the factors. Owing to the present degenerative forces at work in the ostrich we can by selection hope to modify the germ plasm in a minus direc- 
tion, though not in a plus direction, beyond the present limits of the race. It will of course be readily appreciated that this possibility differs altogether from that due to the ordinary selection which may go on in a race of organisms where the germ plasm is static, but where all grades of pure lines may be extracted between extreme limits. Where the germ plasm for a race is static, as demonstrated by Jennings in his work on Paramacium, we can readily understand that no further change is possible by selection within a pure line, as nothing inducing factorial changes is present. If where germinal changes are taking place it is not permissible to think of the factors as changing autonomously we have to assume that some causative agent is present, and may vary in degree in different members and thereby form a basis for selective action.

The same considerations can be applied to the statement: "mixing of germ plasms in fertilization alters hereditary determiners mutually and hence is, in and of itself, a cause of genetic variations." When, for example, two germ plasms, in each of which the causative ag'ent producing loss of factors is at its maximum, become mixed in fertilization it is reasonable to expect that the agent will be intensified and the hereditary determiners will be altered mutually, and some of them drop out. The mixing will be, in and of itself, a cause of genetic variation, which will be expressed by a further losis of remiges.

Though the idea of a causative agent inducing changes in the germ plasm, and varying in degree and also transmissible, is altogether hypothetical yet it is stimulating to further experimental effort. Of the hundreds of ostriches examined not one has been found with less than 33 remiges, hence this number must be regarded as the present minimum of the race. There is every reason to expect that a pure line having this number only can be built up. If by breeding these together a further reduction of plumes should take place we should then be fully justified in assuming that the factors concerned with the 
lost members had dropped out from the. germ plasm, especially if later breeding failed to restore them; selection would have induced a definite change in the germ plasm. Also if a pure line with 42 remiges were established and no further increase occurred we should be warranted in concluding that the factors for the plumes beyond this number had already disappeared from the race and could not be restored; the causative agent could not act in a plus direction. It is unfortunate for such investigations that the ostrich is such a slow breeder. Experiments are however being conducted to determine if further reduction in the 33-plumed birds can be induced, while the building up of a pure 42-plumed race is also in progress, the latter having an important industrial bearing.

In many respects the degeneration phenomena in the ostrich appear to be best understood on the conception of autonomous changes and variations in potency of the germ factors. In the case of the dropping out of plumes during the chick stage the reduction in potency has proceeded so far as to result in entire loss of effectiveness only from the chick stage onwards, while complete loss of factors from the germ plasm may be regarded as the final loss of potency. May not a variation of potency of factors be at the root of many of the so-called fluctuating variations? The explanation seeks for the loss of factors among the autonomous changes in the factors themselves, while the idea of a "causative agent" throws the responsibility for the changes upon some influence external to the factors.

Since the above was written certain results have been obtained which strongly support the idea that it may be possible to induce retrogressive changes in the ostrich. As stated, a loss of scales over the large midille toe has already taken place in a small proportion. Out of twenty southern birds of mixed breeding one showed a single break while out of twenty mixed northern birds a single break occurred in three cases and a double break in two. The results given below are derived from the mating of a 
northern cock without any break and a southern hen in which the break occurs. Of the four offspring reared three are without the break while it occurs in hen No. 179. From the mating of brother and sister four $\mathrm{F}_{2}$ chicks were hatched, two of which have a double break in the scutellation, one shows a single break and one has no break. Thus the proportional loss of scales has greatly increased in the $\mathrm{F}_{2}$ generation.

Scutellation iN $\mathrm{F}_{2}$ Chicks Compared With Parents and Grandparents

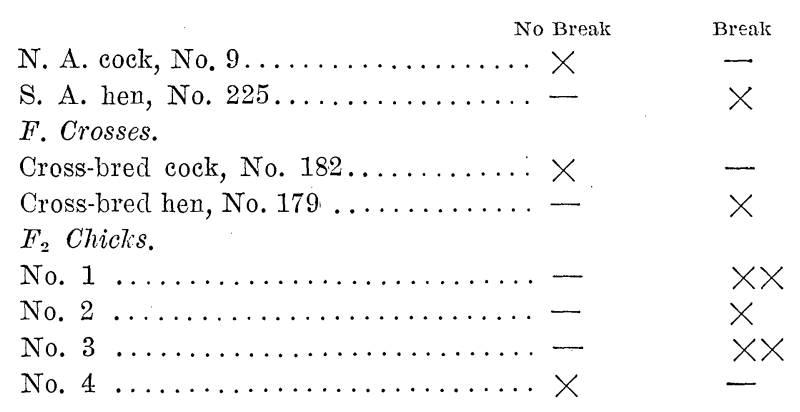

From what has been adduced already we may with good reason admit that an inherent tendency exists in the ostrich towards the loss of certain parts of the fore and hind limbs, and the above result may be regarded as highly suggestive that by inbreeding the inherent tendency towards the loss of scales can be accentuated along definite lines. The accumulation of fuller data must be awaited before the suggestion can be regarded as more than tentative. 